\title{
Selection and Evaluation of Microorganisms for Biocontrol of Fusarium Head Blight of Wheat Incited by Gibberella zeae
}

\author{
N. I. Khan, Postdoctoral Plant Pathologist, Department of Plant Pathology, Ohio State University, Columbus \\ 43210; D. A. Schisler, Research Plant Pathologist, United States Department of Agriculture-Agricultural Research \\ Service (USDA-ARS), National Center for Agricultural Utilization Research (NCAUR), Peoria, IL 61604; M. J. \\ Boehm, Associate Professor of Plant Pathology, Department of Plant Pathology, Ohio State University; and P. J. \\ Slininger, Supervisory Chemical Engineer, and R. J. Bothast, Research Microbiologist, USDA-ARS, NCAUR
}

\begin{abstract}
Khan, N. I., Schisler, D. A., Boehm, M. J., Slininger, P. J., and Bothast, R. J. 2001. Selection and evaluation of microorganisms for biocontrol of Fusarium head blight of wheat incited by Gibberella zeae. Plant Dis. 85:1253-1258.

Gibberella zeae incites Fusarium head blight (FHB), a devastating disease that causes extensive yield and quality losses to wheat and barley. Of over 700 microbial strains obtained from wheat anthers, 54 were able to utilize tartaric acid as a carbon source when the compound was supplied as choline bitartrate in liquid culture. Four tartaric acid-utilizing and three nonutilizing strains reduced FHB in initial tests and were selected for further assays. Antagonists were effective against three different isolates of $G$. zeae when single wheat florets were inoculated with pathogen and antagonist inoculum. All seven antagonists increased 100-kernel weight when applied simultaneously with $G$. zeae isolate Z3639 ( $P \leq 0.05)$. Bacillus strains AS 43.3 and AS 43.4 and Cryptococcus strain $\mathrm{OH} 182.9$ reduced disease severity by $>77,93$, and $56 \%$, respectively. Five antagonists increased 100-kernel weight of plants inoculated with G. zeae isolate DAOM 180378. All antagonists except one increased 100-kernel weight, and four of seven antagonists reduced disease severity $(P \leq 0.05)$ when tested against $G$. zeae isolate Fg-9-96. In spray-inoculation experiments, Bacillus strains AS 43.3 and AS 43.4 and Cryptococcus strains $\mathrm{OH}$ 71.4 and $\mathrm{OH} 182.9$ reduced disease severity, regardless of the sequence, timing, and concentration of inoculum application $(P \leq 0.05)$, though 100-kernel weight did not always increase when antagonists were applied $4 \mathrm{~h}$ after inoculum of $G$. zeae. Overall, 4 of 54 isolates that utilized tartaric acid in vitro were effective against $G$. zeae versus only 3 of 170 isolates tested that did not utilize tartaric acid ( $P \leq 0.05, \chi$-square test of goodness of fit), demonstrating the potential benefit of prescreening candidate antagonists of FHB for their ability to utilize tartaric acid. Biological control shows promise as part of an integrated pest management program for managing FHB.
\end{abstract}

Additional keywords: Fusarium graminearum, scab of wheat

Fusarium head blight (FHB), also known as scab of wheat, pink mold, whiteheads, and tombstone scab, is responsible for extensive damage of wheat in humid

\section{Corresponding author: D. A. Schisler}

E-mail: Schislda@ncaur.usda.gov

This work was made possible in part from funding provided by the U.S. Wheat and Barley Scab Initiative.

Mention of trade names or commercial products in this article is solely for the purpose of providing specific information and does not imply recommendation or endorsement by the USDA or The Ohio State University. Salaries and research support provided by State and Federal funds appropriated to the Ohio Agricultural Research and Development Center, The Ohio State University.

Accepted for publication 15 August 2001.

Publication no. D-2001-1010-01R

This article is in the public domain and not copyrightable. It may be freely reprinted with customary crediting of the source. The American Phytopathological Society, 2001. and semihumid regions of the world $(2,12)$. The primary causal agent of scab of wheat in North America, Gibberella zeae $($ anamorph $=$ Fusarium graminearum $)$, can produce potent toxins, such as the estrogenic toxin zearalenone (8) and the trichothecene deoxynivalenol (DON, vomitoxin) $(14,22)$. DON can inhibit amino acid incorporation and protein production in plant tissues (4), and grain heavily contaminated by the toxin is frequently unsuitable for human consumption and may be refused as feed (27). Infection of wheat kernels by $G$. zeae reduces grain yield and affects grain quality (5). The infection of seed reduces seed germination, seedling vigor, and plant emergence (3).

Chemical control and resistant cultivars are potential options for reducing the severity of FHB. Registered fungicides can be effective; however, residue and cost concerns are potential problems with chemical usage. All wheat cultivars currently in production are vulnerable to infection. Some success in controlling scab can be achieved by plowing fields after harvest to bury crop residues, but the pref- erence for minimal-tillage agriculture renders this alternative less attractive (6). Biological control, though currently not available commercially for FHB, would offer another option for reducing the disease (11). The feasibility of biologically controlling this disease has been demonstrated $(9,13,24)$.

Anthesis is a crucial time for the onset of FHB, with anthers promoting infection of wheat heads by G. zeae (25). Choline and betaine are found in wheat anthers and are stimulatory to the growth of conidial germ tubes of G. zeae (26). We surmised that microorganisms isolated from wheat anthers would be a good source of putative biocontrol agents and that information on carbon utilization by anther colonists could prove useful for selecting and formulating biocontrol strains. During our study, highperformance liquid chromatography (HPLC) analysis of culture broths containing individual anther colonists and choline in the form of choline bitartrate identified colonists capable of utilizing tartaric acid but was ineffective in identifying those capable of metabolizing choline. Fortuitously, a higher percentage of tartaric acidutilizing microbes exhibited superior FHB biocontrol capabilities than did nonutilizing microbes. Tartaric acid is a compound that is poorly utilized by G. zeae as a carbon source (D. Schisler, unpublished data) and is a readily available byproduct in the processing of grapes and other fruits for juice and wine (1).

In previous investigations on biologically controlling plant disease, Schisler and coworkers (19) demonstrated that isolates of a fungal pathogen can differ substantially in their amenability to being suppressed with biocontrol agents. Whether biocontrol strains also vary in their relative effectiveness depending on the isolate of G. zeae used in a bioassay is not known. Additionally, the importance of the order and the timing of arrival of pathogen and biocontrol agent inoculum is not known for this biocontrol system.

Our objectives for this study were to (i) select putative antagonists of $G$. zeae based on obtaining microbes from anther tissue and assay colonists for their ability to utilize tartaric acid, (ii) screen putative antagonists for their efficacy against $G$. zeae and determine whether antagonist 
efficacy depends on pathogen isolate, and (iii) determine if the order or timing of pathogen and biocontrol inoculations im-

\section{MATERIALS AND METHODS}

Isolation of anther colonists. In the spring of 1997, anthers were collected from flowering wheat plants across Illinois and Ohio, two states that had experienced recent FHB epidemics. Anthers were removed from wheat flowers using sterilized jeweler's forceps and placed in vials containing $10 \%$ ( vol/vol) glycerol held at approximately $5^{\circ} \mathrm{C}$. Vials then were frozen at $-80^{\circ} \mathrm{C}$. More than 400 anther collections were obtained. To isolate individual strains of microorganisms from anthers, vials were thawed until the glycerol suspension reached $4^{\circ} \mathrm{C}$. Vials then were mixed using a vortex mixer for $30 \mathrm{~s}$ to liberate microorganisms from anther surfaces. Suspensions containing microorganisms were serially diluted using sterile, weak, $\mathrm{pH} 7.2$ phosphate buffer $\left(0.004 \%\right.$ [wt/vol] $\quad \mathrm{KH}_{2} \mathrm{PO}_{4}$ buffer with $0.019 \%$ [wt/vol] $\mathrm{MgCl}_{2}$; Aid Pack, Gloucester, MA). Samples were plated onto a variety of solidified media (agar at $18 \mathrm{~g} /$ liter), including corn steep liquor (Solulys-AST at $10 \mathrm{~g} /$ liter [Roquette Corporation, Gurnee, IL], yeast extract at 1 g/liter, $\mathrm{KH}_{2} \mathrm{PO}_{4}$ at $2 \mathrm{~g} /$ liter, $\mathrm{K}_{2} \mathrm{HPO}_{4}$ at 2 g/liter, $\mathrm{MgSO}_{4} \cdot 7 \mathrm{H}_{2} \mathrm{O}$ at $1 \mathrm{~g} /$ liter, $\mathrm{NaCl}$ at $0.1 \mathrm{~g} / \mathrm{liter}$ glucose at $15 \mathrm{~g} / \mathrm{liter}, \mathrm{pH}$ 6.8), malt yeast extract (yeast extract at 3.0 $\mathrm{g} /$ liter, malt extract at $3.0 \mathrm{~g} / \mathrm{liter}$, glucose at $10 \mathrm{~g} /$ liter, and peptone [type IV] at 5.0 g/liter, $\mathrm{pH}$ 3.5), and one-fifth strength Tryptic soy broth agar (TSBA/5, pH 6.8; Difco Laboratories, Detroit). The corn steep liquor medium was selected to reprecommercial use. The TSBA/5 medium was selected as a general purpose medium that supports the growth of a wide variety of pact the suppression of FHB. sent a production medium that, in liquid state, could be economically feasible for

microorganisms, whereas the malt yeast extract medium was selected to isolate yeasts preferentially. Single colonies of antagonists showing distinct growth morphology were streaked for purity on TSBA/5. In all, 738 microbial isolates were purified and preserved in $10 \%$ (wt/vol) glycerol at $-80^{\circ} \mathrm{C}$ until needed.

Stage 1 antagonist selection: tartaric acid utilization. All putative antagonists were tested for tartaric acid utilization as determined by HPLC analysis of antagonist culture broths containing choline bitartrate. Isolates were grown on TSBA/5 and harvested cells used to inoculate (optical density [OD] of approximately 0.8 at 620 $\mathrm{nm}$ wavelength light $\left.\left[A_{620}\right]\right) 10 \mathrm{ml}$ of a minimal salt medium that contained choline bitartrate at $1 \mathrm{~g} /$ liter and urea at 1.26 $\mathrm{g} /$ liter. Cultures were incubated at $25^{\circ} \mathrm{C}$ and $250 \mathrm{rpm}$ for $48 \mathrm{~h}$ in a shaker incubator. Colonized broths were centrifuged $(5,000$ rpm or approximately 2,000 relative centrifugal force $(\mathrm{RCF})$ for $10 \mathrm{~min}$ at $4^{\circ} \mathrm{C}$ ) and the supernatant was passed through $0.2-\mu \mathrm{m}$ filters (Lida Manufacturing Corp, Kenosha, WI). For HPLC analysis of culture filtrates, a 30-by-4.6-mm cation $\mathrm{H}$ cartridge precolumn (Biorad, Hercules, CA), an Aminex HPX-87H, 300-by-7.8$\mathrm{mm}$ column (Biorad), and a Waters 410 refractive index detector (Milford, MA) were used. The mobile phase for carrying filtrate sample was acidified $\mathrm{H}_{2} \mathrm{O}(0.017 \mathrm{~N}$ $\mathrm{H}_{2} \mathrm{SO}_{4}$ ) at a flow rate of $0.6 \mathrm{ml} / \mathrm{min}$. Of the original 738 isolates of microorganisms assayed, 54 metabolized tartaric acid; all were selected for use in a two-head plant bioassay of biocontrol efficacy against FHB, as were an additional 188 randomly selected isolates that did not use tartaric acid.

Stage 2 antagonist selection: two-head plant bioassay. Two seedlings of hard red spring wheat (cv. Norm) per 19-cm-diameter pot were grown in an airsteam pasteur-

Table 1. Antagonist strain designation and identification of bacteria and yeasts that reduce the severity of Fusarium head blight of wheat

\begin{tabular}{|c|c|c|}
\hline Antagonist & NRRL accession no. ${ }^{u}$ & Identification \\
\hline AS 43.3 & B-30210 & Bacillus subtilis/amyloliquefaciens $v$ \\
\hline AS 43.4 & B-30211 & Bacillus subtilis/amyloliquefaciens $\mathrm{v}$ \\
\hline OH 71.4 & Y-30213 & Cryptococcus sp. (syn. Torula aurea) $)^{\mathrm{w}}$ \\
\hline OH 72.4 & Y-30214 & $\mathrm{ND}^{\mathrm{x}}$ \\
\hline OH 131.1 & B-30212 & Bacillus subtilis $^{\mathrm{y}}$ \\
\hline OH 181.1 & Y-30215 & Cryptococcus sp. nov. ${ }^{\mathrm{w}}$ \\
\hline OH 182.9 & Y-30216 & Cryptococcus nodaensis sp. nov. ${ }^{\mathrm{Z}}$ \\
\hline
\end{tabular}

\footnotetext{
" NRRL patent culture collection, National Center for Agricultural Utilization Research, Peoria, IL.

${ }^{v}$ Identification by Deutsche Sammlung von Mikroorganismen und Zellkulturen GmbH (DSMZ), Braunschweig, Germany, based on 16S rDNA sequence homologies and biochemical and physiological tests of taxonomic utility.

${ }^{\mathrm{w}}$ Identification based on nucleotide sequence divergence in domain D1/D2 of large subunit 26S rDNA and on divergence in internal transcribed spacer (ITS) 1/5.8/ITS2 rDNA. (C. P. Kurtzman, personal communication).

$x$ Yeast, not determined.

${ }^{y}$ Identification by MIDI Labs, Newark, DE, based on 16S rDNA sequence homologies and biochemical and physiological tests of taxonomic utility.

${ }^{\mathrm{z}}$ Identification based on nucleotide sequence divergence in domain D1/D2 of large subunit 26S rDNA and on divergence in ITS 1/5.8/ITS2 rDNA. (C. P. Kurtzman, personal communication, and $16)$.
}

ized $\left(60^{\circ} \mathrm{C}\right.$ for $\left.30 \mathrm{~min}\right)$ potting mix (Terralite Redearth mix; W. R. Grace, Cambridge, MA) in a growth chamber $\left(25^{\circ} \mathrm{C}\right.$, $14 \mathrm{~h}$ of light/day, $\left.600 \mu \mathrm{mol} /\left[\mathrm{m}^{2} / \mathrm{sec}\right]\right)$ for approximately 8 weeks prior to use in bioassays. Conidial inoculum of $G$. zeae isolate Z-3639 was produced on clarified V8 juice agar (CV8 agar) under fluorescent light at $12 \mathrm{~h} /$ day for 7 days at $24^{\circ} \mathrm{C}$ (17). Suspensions of macroconidia were obtained by flooding the surface of colonized CV8 agar with $\mathrm{PO}_{4}$ buffer and dislodging conidia using a sterile inoculating loop. At 2 or 3 days before use, microbial strains were recovered from storage in $10 \%$ glycerol at $-80^{\circ} \mathrm{C}$ by briefly warming vials at room temperature and streaking partially thawed glycerol onto TSBA/5. Cells were restreaked for purity after $48 \mathrm{~h}$. Biomass of microbial strains was collected by rolling a sterile cotton swab on a 18- to 24-h culture on TSBA/5 and suspending the biomass in $\mathrm{PO}_{4}$ buffer. Inoculum for wheat heads was prepared that contained antagonist suspension (OD approximately 0.2 to 0.3 at $\mathrm{A}_{620}, 5 \times 10^{5}$ conidia $/ \mathrm{ml}$ and $0.04 \%$ [vol/vol] Tween 80; Sigma-Aldrich, St. Louis). To initiate the two-head plant bioassay for antagonists of G. zeae, the middle florets of two heads were coinoculated with $10 \mu \mathrm{l}$ of a microbial suspension. Heads were inoculated within 2 to 4 days of flowering. Heads inoculated only with conidia of $G$. zeae served as controls. After inoculation, wheat plants were misted with water, incubated in a plastic humidity chamber for $72 \mathrm{~h}$ at approximately $22^{\circ} \mathrm{C}$, and transferred to greenhouse benches. Plastic humidity chambers consisted of a PVC pipe frame covered with clear plastic. FHB severity was visually estimated using a 0 -to- $100 \%$ scale (23) 16 days after inoculation. Twenty-six strains, including nine tartaric acid-utilizers, prevented any visible FHB disease development and were selected for second-stage testing of efficacy against $G$. zeae.

Stage 3 antagonists selection: multiple-head plant bioassay. Management of wheat growth and preparation of G. zeae Z-3639 conidial inoculum were conducted as described above. Biomass of microbial strains was produced in liquid culture. Ten milliliters of semidefined complete liquid medium (20) in 50-ml Erlenmeyer flasks was inoculated to an OD of 0.10 at $\mathrm{A}_{620}$ with cells grown on TSBA/5 for $24 \mathrm{~h}$. Flasks then were incubated in a shaker incubator at $250 \mathrm{rpm}$ and $25^{\circ} \mathrm{C}$ for $48 \mathrm{~h}$. At anthesis, $10 \mu \mathrm{l}$ of an inoculum mixture of G. zeae $\left(5 \times 10^{5}\right.$ conidia/ml $)$ and cells of a putative antagonist (48-h colonized broth diluted to $25 \%$ with $\mathrm{PO}_{4}$ buffer; approximately $2 \times 10^{9}$ and $5 \times 10^{8} \mathrm{CFU} / \mathrm{ml}$ for bacteria and yeast strains, respectively) were used to inoculate single florets on 16 wheat heads (4 heads per replication, four replications/treatment). Plants were scored for disease severity after 16 days. Of the 26 
strains assayed, 7 reduced FHB severity by 25 to $80 \%$ ( $P \leq 0.10$, data not shown $)$ and were selected for further studies.

Antagonist bioassay against $G$. zeae isolates of different origin. Multiple-head plant bioassays were conducted as described above using the seven antagonists selected. Isolates of $G$. zeae used in the bioassays were Z3639, DAOM 180378, and Fg-9-96, originally isolated from Kansas, Ontario (Canada), and Ohio, respectively. Heads inoculated only with $G$. zeae conidia or only with $\mathrm{PO}_{4}$ buffer served as controls. Disease severity was rated as described above and 100-kernel weight was determined after harvest. G. zeae was recovered via plating symptomatic tissue from randomly selected heads onto CV8 medium. There were four heads per replication and four replications per treatment distributed in a completely randomized design. Experiments with each isolate of $G$. zeae were performed at least twice. Data from repeated experiments were pooled because statistical analysis demonstrated that experiment interactions were rarely significant. Disease severity data were normalized when needed using the arcsine transformation before analysis of variance (ANOVA). Means were separated at $P \leq 0.05$ using Fisher's protected least significance difference test (PC SAS, ver. 6.12; SAS Institute, Inc., Cary, NC). Relative performance indices of efficacy $\left(\mathrm{RPI}_{\text {efficacy }}\right)$ were calculated for each antagonist performance against each isolate of G. zeae. For each experiment, an $\mathrm{RPI}_{\text {efficacy }}$ value was calculated for each replication of each antagonist treatment. These values were used to calculate an average $\mathrm{RPI}_{\text {efficacy }}$ for each antagonist strain and for ANOVA and mean separation of antagonist $\mathrm{RPI}_{\text {efficacy }}$ averages. Relative performance indices allow different types of data to be compared using a standard scale and are dimensionless values that will theoretically range from 0 to 100 , in which $100=$ maximum antagonist efficacy relative to the other antagonist strains tested. Assuming FHB severity ratings are normally distributed, $Z$ (the standard normal variate) will range from -2 to +2 (95\% probability) when $Z=(X-\bar{X}) / s$, where $X$ is a single disease rating value observed for an antagonist strain, and $\bar{X}$ and $s$ are the average and standard deviation, respectively, of all values obtained for all antagonist strains (21). $\mathrm{RPI}_{\text {efficacy }}$ then is calculated as: $|(Z-2)| \times$ 25 . For data sets where some $Z$ values fall outside the range of -2 to $+2, \mathrm{RPI}_{\text {efficacy }}$ is more accurately calculated as $(2-Z) \times 25$.

Influence of order and timing of inoculum application on FHB disease. Management of wheat growth, microbial biomass preparation in liquid culture, and G. zeae conidial inoculum preparation were conducted as described above. A spray inoculation method was used to mimic the arrival of inoculum at the infection court in the field. An aqueous suspension (2 ml) containing $G$. zeae isolate $\mathrm{Z} 3639$ at $5 \times 10^{5}$ conidia/ml and $0.04 \%$ Tween 80 was applied as a mist ( $\mathrm{Spr} \bullet \mathrm{Tool}$; North American Professional Products, Woodstock, IL) over four wheat heads, immediately before or after and $4 \mathrm{~h}$ before or after treating heads with $5 \mathrm{ml}$ of an aqueous suspension containing antagonist cells. Antagonist cells were applied at 10 or $50 \%$ of 48 -h colonized broth. Heads sprayed only with conidia of $G$. zeae served as controls. Treatments were distributed in a completely randomized design $(n=4)$. Experiments were performed at least twice. Data analysis was as described above for separating treatment means from controls. Orthogonal contrasts provided analysis of the effect of antagonist concentration on FHB severity.

\section{RESULTS}

Antagonist selection. Approximately $7 \%$ (54 strains) of the strains recovered from anthers utilized tartaric acid in liquid culture. Tartaric acid-utilizers and an additional 188 randomly selected strains were used in replicated greenhouse plant bioassays to determine strain efficacy in reducing FHB. Twenty-six strains, including eight tartaric acid-utilizers, prevented the development of any visible FHB symptoms in two-head plant bioassays. Of the 26 strains tested (Table 1), 7, including 4 tartaric acid-utilizers, were superior in significantly reducing FHB disease in multiple-head plant bioassays $(P \leq 0.10$, data not shown). A higher proportion of tartaric acid-utilizing strains (4 of 54) were superior biocontrol strains than were nonutilizers ( 3 of 188) $(P \leq 0.05, \chi$-square test of goodness of fit). None of the seven strains utilized choline in liquid culture (N. Khan, unpublished data).

Antagonist bioassay against G. zeae isolates of different origin. Bacillus strains AS 43.3 and AS 43.4, and Cryptococcus strain $\mathrm{OH} 182.9$ (Table 1) reduced FHB disease severity by 77,93 , and $56 \%$, respectively, in assays against $G$. zeae isolate Z3639 ( $P \leq 0.05$, Table 2$)$. All seven antagonists reduced FHB as indicated by increased 100-kernel weight of microbially treated wheat heads $(P \leq 0.05$, Table 2$)$. Treatments with antagonist strains AS 43.3, AS 43.4, and $\mathrm{OH} 182.9$ increased 100 -kernel weight by 140,144 , and $100 \%$, respectively. In bioassays against isolate DAOM 180378 of G. zeae, only strains AS 43.3 and AS 43.4 reduced disease as measured by either reduction in disease severity or disease incidence. Five strains increased 100-kernel weight, whereas Cryptococcus sp. OH 181.1 decreased 100-kernel weight (Table 2). Conversely, in bioassays using isolate Fg-9-96 of G. zeae, all antagonists except yeast $\mathrm{OH} 72.4$ increased 100-kernel weight and four of seven antagonists reduced disease severity $(P \leq 0.05$, Table 2$)$. Overall, strains AS 43.3 and AS 43.4 consistently reduced FHB disease regardless of the isolate of G. zeae used in the bioassays (Table 2). Cryptococcus spp. $\mathrm{OH} 71.4$ and $\mathrm{OH} 182.9$ reduced disease caused by all three isolates of $G$. zeae as quantified by at least one of the disease parameters measured. The remaining three antagonists were effective against two of the three isolates of $G$. zeae tested. Antagonist rankings based on $\mathrm{RPI}_{\text {efficacy }}$ varied depending on the isolate of G. zeae (Table 3). Significant differences in the $\mathrm{RPI}_{\text {efficacy }}$ values obtained for antagonist strains AS 43.4,

Table 2. Influence of microbial antagonists on Fusarium head blight incited by three isolates of Gibberella zeae on hard red spring wheat cultivar Norm ${ }^{\mathrm{y}}$

\begin{tabular}{|c|c|c|c|c|c|c|c|c|c|}
\hline \multirow[b]{3}{*}{ Treatment } & \multicolumn{9}{|c|}{ G. zeae isolate $^{\mathrm{z}}$} \\
\hline & \multicolumn{3}{|c|}{ Z 3639} & \multicolumn{3}{|c|}{ DAOM 180378} & \multicolumn{3}{|c|}{ Fg-9-96 } \\
\hline & DS (\%) & DI (\%) & 100-kw (g) & DS (\%) & DI (\%) & 100-kw (g) & DS $(\%)$ & DI (\%) & $100-\mathrm{kw}(\mathrm{g})$ \\
\hline G. zeae alone & 90 & 95 & 1.5 & 76 & 91 & 1.8 & 54 & 66 & 3.2 \\
\hline Buffer alone & NT & NT & NT & $0^{*}$ & $0^{*}$ & $4.2^{*}$ & $0 *$ & $0^{*}$ & $4.3^{*}$ \\
\hline AS 43.3 & $20 *$ & 63 & $3.6^{*}$ & $17 *$ & $41 *$ & $3.7 *$ & $3 *$ & $3^{*}$ & $4.0^{*}$ \\
\hline AS 43.4 & $6^{*}$ & $46^{*}$ & $3.9^{*}$ & $14 *$ & $31 *$ & $3.6^{*}$ & $11^{*}$ & $12 *$ & $3.8^{*}$ \\
\hline OH 71.4 & 78 & 82 & $1.9^{*}$ & 75 & 87 & $2.0^{*}$ & $3 *$ & $12^{*}$ & $4.0^{*}$ \\
\hline $\mathrm{OH} 72.4$ & 82 & 89 & $1.8^{*}$ & 73 & 84 & $2.0^{*}$ & 51 & 56 & $2.8^{*}$ \\
\hline OH 131.1 & 79 & 89 & $2.1^{*}$ & 75 & 87 & 1.9 & $26^{*}$ & $34 *$ & $3.8 *$ \\
\hline OH 181.1 & 82 & 89 & $1.9 *$ & 88 & 91 & $1.7 *$ & 44 & 50 & $4.0^{*}$ \\
\hline OH 182.9 & $39 *$ & $72^{*}$ & $3.0^{*}$ & 69 & 84 & $2.0^{*}$ & 51 & 65 & $3.5^{*}$ \\
\hline
\end{tabular}

y The middle floret of a central spikelet of a wheat head was coinoculated with $10 \mu \mathrm{l}$ of a 48-h antagonist-colonized broth diluted to $25 \%$ with $\mathrm{PO}_{4}$ buffer $\left(10^{8}\right.$ to $\left.10^{9} \mathrm{CFU} / \mathrm{ml}\right)$ and G. zeae conidia $\left(5 \times 10^{5}\right.$ conidia $\left./ \mathrm{ml}\right)$.

${ }^{\mathrm{z}} \mathrm{DS}=$ disease severity, DI $=$ disease incidence, $100-\mathrm{kw}=100$-kernel weight, NT $=$ not tested. Within a column, means followed by an asterisk are significantly different from the $G$. zeae control (Fisher's protected least significant difference, $P \leq 0.05$ ). 
$\mathrm{OH} 71.4$, and $\mathrm{OH} 182.9$ when assayed against the three isolates of G. zeae indicated that the relative efficacy of these antagonist strains was dependent on the pathogen isolate used to incite disease.

Influence of order and timing of inoculum application on FHB disease. In spray-inoculation experiments, all antagonists significantly reduced disease severity, regardless of the sequence, timing, and concentration of inoculum application $(P \leq$ 0.05 , Table 4), though some antagonists did not increase 100-kernel weight when inoculum of $G$. zeae was applied $4 \mathrm{~h}$ before the antagonist (Table 5). The comparison of antagonist concentration response as measured by orthogonal contrasts for disease severity indicated no significant effect of concentration for all the antagonists except AS 43.4 when G. zeae inoculum was applied $4 \mathrm{~h}$ before the antagonist (Table 6). When pathogen inoculum was applied immediately before or after antagonists, antagonist concentration influenced disease severity in some cases, though higher antagonist concentration was

Table 3. Comparison of efficacy relative performance indices ( $\mathrm{RPI}_{\text {efficacy }}$ ) for seven antagonists when tested against three isolates of Gibberella zeae on flowering wheat heads ${ }^{\mathrm{z}}$

\begin{tabular}{lccc}
\hline & \multicolumn{3}{c}{ RPI $_{\text {efficacy }}$ for $\boldsymbol{G}$. zeae isolates } \\
\cline { 2 - 4 } Treatment & $\mathbf{Z ~ 3 6 3 9}$ & DAOM 180378 & Fg-9-96 \\
\hline AS 43.3 & $73.8 \mathrm{a}$ & $82.2 \mathrm{a}$ & $71.0 \mathrm{a}$ \\
AS 43.4 & $84.4 \mathrm{a}$ & $84.6 \mathrm{a}$ & $64.2 \mathrm{~b}$ \\
OH 71.4 & $34.9 \mathrm{~b}$ & $37.4 \mathrm{~b}$ & $71.5 \mathrm{a}$ \\
OH 72.4 & $32.3 \mathrm{a}$ & $38.9 \mathrm{a}$ & $28.9 \mathrm{a}$ \\
OH 131.1 & $36.0 \mathrm{a}$ & $37.5 \mathrm{a}$ & $50.9 \mathrm{a}$ \\
OH 181.1 & $31.4 \mathrm{a}$ & $27.3 \mathrm{a}$ & $34.8 \mathrm{a}$ \\
OH 182.9 & $57.1 \mathrm{a}$ & $42.1 \mathrm{ab}$ & $28.7 \mathrm{~b}$ \\
\hline
\end{tabular}

${ }^{\mathrm{z}}$ The hard red spring wheat cultivar Norm was used in greenhouse bioassays. RPI efficacy $_{\text {values were }}$ calculated using disease severity data from at least two experiments, each with four replicates per treatment. Within a row, means followed by the same lower-case letter are not significantly different (Fisher's protected least significant difference, $P \leq 0.05$ ).

Table 4. Percent Fusarium head blight disease severity when varying the time and sequence of pathogen and antagonist inoculum application to wheat heads

\begin{tabular}{lcccc}
\hline & \multicolumn{4}{c}{ Gibberella zeae (Z3639) inoculum applied } \\
\cline { 2 - 5 } Antagonist $^{\mathbf{z}}$ & $\mathbf{4}$ h before & Immed. before & Immed. after & 4 h after $^{\text { }}$ \\
\hline None (control) & 59 & 86 & 81 & 85 \\
AS 43.3 (10\%) & $13^{*}$ & $2^{*}$ & $3^{*}$ & $21^{*}$ \\
AS 43.3 (50\%) & $5^{*}$ & $1^{*}$ & $0^{*}$ & $15^{*}$ \\
AS 43.4 (10\%) & $42^{*}$ & $3^{*}$ & $3^{*}$ & $30^{*}$ \\
AS 43.4 (50\%) & $19^{*}$ & $33^{*}$ & $0^{*}$ & $18^{*}$ \\
OH 71.4 (10\%) & $26^{*}$ & $24^{*}$ & $18^{*}$ & $49^{*}$ \\
OH 71.4 (50\%) & $28^{*}$ & $51^{*}$ & $37^{*}$ & $63^{*}$ \\
OH 182.9(10\%) & $43^{*}$ & $64^{*}$ & $60^{*}$ & $45^{*}$ \\
OH 182.9 (50\%) & $43^{*}$ & $49^{*}$ & $60^{*}$ & $58^{*}$ \\
\hline
\end{tabular}

y Time before and after antagonist; Immed. = immediately. Within a column, means followed by an asterisk are significantly different from the control (Fisher's protected least significant difference, $P$ $\leq 0.05$ ).

${ }^{\mathrm{z}}$ Antagonists were applied as a mist at concentrations of 10 or $50 \%$ of a 48 -h (early stationary growth phase) antagonist-colonized, semidefined complete liquid medium.

Table 5. One-hundred-kernel weights when varying the time and sequence of pathogen and antagonist inoculum application to wheat heads

\begin{tabular}{lcccc}
\hline & \multicolumn{4}{c}{ Gibberella zeae (Z3639) inoculum applied } \\
\cline { 2 - 5 } Antagonist $^{\mathbf{z}}$ & $\mathbf{4}$ h before & Immed. before & Immed. after & 4 h after \\
\hline None (control) & 1.8 & 1.6 & 1.7 & 1.4 \\
AS 43.3 (10\%) & $2.4^{*}$ & $3.4^{*}$ & $3.4^{*}$ & $2.6^{*}$ \\
AS 43.3 (50\%) & $2.6^{*}$ & $3.6^{*}$ & $3.1^{*}$ & $2.7^{*}$ \\
AS 43.4 (10\%) & $2.5^{*}$ & $3.3^{*}$ & $3.2^{*}$ & $2.2^{*}$ \\
AS 43.4 (50\%) & 1.7 & $3.0^{*}$ & $3.1^{*}$ & $2.6^{*}$ \\
OH 71.4 (10\%) & 1.9 & $2.3^{*}$ & $2.8^{*}$ & $2.4^{*}$ \\
OH 71.4 (50\%) & $2.4^{*}$ & $2.6^{*}$ & $2.5^{*}$ & $2.0^{*}$ \\
OH 182.9(10\%) & 1.9 & $2.3^{*}$ & $2.3^{*}$ & $2.7^{*}$ \\
OH 182.9 (50\%) & 1.8 & $2.2^{*}$ & $2.3^{*}$ & $2.0^{*}$ \\
\hline
\end{tabular}

y Time before and after antagonist; Immed. = immediately. Within a column, means followed by an asterisk are significantly different from the control (Fisher's protected least significant difference, $P$ $\leq 0.05)$.

${ }^{\mathrm{z}}$ Antagonists were applied as a mist at concentrations of 10 or $50 \%$ of a 48 -h (early stationary growth phase) antagonist-colonized, semidefined complete liquid medium. not consistently associated with greater reduction in disease severity (Table 6). All antagonists showed some significant differences in concentration effect on 100kernel weight (Table 7), although increased antagonist concentration was not always associated with increased efficacy in reducing FHB disease. Bacillus strains were generally more effective in reducing FHB severity than were yeast isolates $(P \leq$ 0.05 , data not shown). Bacillus strains decreased FHB severity irrespective of their method of application on the wheat head (i.e., whether applied as a spray mist or via inoculation of single wheat florets). However, yeasts were more effective in suppressing FHB severity when applied as a mist than when applied to single florets (Tables 2, 4, and 5).

\section{DISCUSSION}

Selection of putative antagonists for biological control of plant diseases usually involves collecting and screening large numbers of microbial isolates to enhance the probability of discovering a highly effective strain. Screening a large number of putative antagonists through the laborintensive technique of plant bioassay may not be a feasible strategy for the initial selection of candidate antagonists if plant material is difficult to manipulate or produce. Therefore, various tests for the preselection of putative antagonists and the narrowing of the number of antagonists for bioassay on plants have been attempted, including in vitro antibiosis tests conducted on nutrient agar. However, the test medium used in these assays can influence the degree of antibiosis shown by putative antagonists $(7,18)$. Additionally, the correlation between in vitro antibiosis on agar medium and biological control in situ is frequently inconsistent $(10,15)$.

From a collection of 738 microorganisms obtained from wheat anthers, we selected 54 microbial strains that utilized tartaric acid and 188 that did not. As a relatively inexpensive byproduct from the production of grape and other fruit juices (1), tartaric acid has potential for use in formulations of tartaric acid-utilizing antagonists because the compound is poorly utilized by G. zeae (D. A. Schisler, unpublished data). Of 54 tartaric acid-utilizing isolates, $4(7.4 \%)$ consistently reduced FHB disease severity and increased 100kernel weights. In contrast, only 3 of 188 microbial isolates $(1.6 \%)$ that did not utilize tartaric acid were successful in reducing FHB. This reduction in disease was obtained using microbial biomass produced in a liquid culture medium that should be affordable for use on a commercial scale. Testing candidate microbes for their ability to utilize tartaric acid may be a useful preliminary screen for narrowing the search for FHB antagonists. Employing this screening method substantially reduced the number of strains that advanced 
to the labor-intensive step of plant testing, yet provided a high percentage of those strains that were effective. Though tartaric acid is present in many fruits, we are not aware of any reports of its presence in wheat tissues. We are currently investigating this possibility. Choline is present in wheat anthers and stimulates early germ tube growth of G. zeae (26). Surprisingly, none of the top FHB antagonists identified in this study utilized choline in liquid culwith potential to biologically control FHB do (N. Khan, unpublished data).

The preliminary screening of putative antagonists also included recovering isolates from anthers on Solulys medium, a medium composed of relatively inexpensive nutrient sources that could be economically feasible for use in commercial production of microbial biomass. Additionally, biomass of putative antagonists was produced in liquid culture early in the selection process. Production of antagonists in liquid versus solid media and in liquid media of differing composition can affect the relative and overall performance of the antagonists produced (19). Even during the early stages of antagonist selection, therefore, antagonist biomass should be produced using a medium feasible for use in commercial production.

All seven of the antagonists chosen from the multiple-head plant bioassays reduced FHB disease symptoms incited by two of the three isolates of G. zeae, and four of the strains reduced symptoms incited by all three isolates of $G$. zeae. Interestingly, pathogen isolate influenced the relative efficacy of antagonist strains AS 43.4, OH 71.4, and $\mathrm{OH} 182.9$ as determined by ture, though recently discovered strains $\mathrm{RPI}_{\text {efficacy }}$ values. It is not known whether

this indicates that these strains will be more variable in performance than the other antagonists when tested in field environments where a diversity of $G$. zeae genotypes would be encountered. Differences in relative performance between potato dry rot antagonists when tested against a variety of isolates of $G$. pulicaris also have been reported (19).

Bacillus strains AS 43.3 and AS 43.4 consistently decreased FHB disease severity, increased 100-kernel weight, or both, regardless of the method of antagonist application utilized. Although determining the mode of action of antagonists was not part of this study, antibiosis may be a mechanism of biological control for strains AS 43.3 and AS 43.4 because they inhibited the growth of $G$. zeae in petri plate antagonism tests (N. Khan, unpublished data). The yeast isolates in this study did not demonstrate petri plate antagonism of G. zeae but were all utilizers of tartaric acid. Interestingly, all of the yeast isolates were more successful in reducing the severity of FHB when applied as a mist compared with when inoculated at a single point on a wheat head. This may be due to the fact that, in point inoculation, pathogen inoculum is placed within a floret, thereby directly providing an infection court to the pathogen and limiting the opportunity for yeasts to compete with $G$. zeae for nutrients before the pathogen has successfully invaded the host tissue. On the other hand, when sprayed on the external surfaces of the wheat head along with pathogen inoculum, yeasts may have an increased opportunity to compete for the nutrients present at the infection court, especially on anthers (25).

Although these antagonist strains were effective against three different isolates of

Table 6. Orthogonal contrast analysis of the effect of concentration of antagonist on Fusarium head blight severity

\begin{tabular}{lcccc}
\hline & \multicolumn{3}{c}{$\boldsymbol{P}>$ F for Gibberella zeae } & (Z3639) inoculum applied \\
\cline { 2 - 5 } Orthogonal contrast $^{\mathbf{z}}$ & $\mathbf{4}$ h before & Immed. before & Immed. after & 4 h after \\
\hline AS 43.3 (10\%) vs. (50\%) & 0.197 & 0.893 & 0.652 & 0.496 \\
AS 43.4 (10\%) vs. (50\%) & 0.001 & 0.001 & 0.629 & 0.125 \\
OH 71.4 (10\%) vs. (50\%) & 0.848 & 0.001 & 0.007 & 0.115 \\
OH 182.9(10\%) vs. (50\%) & 0.988 & 0.025 & 0.989 & 0.124 \\
\hline
\end{tabular}

y Time before and after antagonist; Immed. = immediately.

${ }^{\mathrm{z}}$ Antagonists were applied at concentrations of 10 or $50 \%$ of a 48 -h (early stationary growth phase) antagonist-colonized, semidefined complete liquid medium.

Table 7. Orthogonal contrast analysis of the effect of concentration of antagonist on 100-kernel weights of wheat heads inoculated with Gibberella zeae (Z3639)

\begin{tabular}{lcccc}
\hline & \multicolumn{3}{c}{$P>$ F for G. zeae (Z3639) inoculum applied } \\
\cline { 2 - 5 } Orthogonal contrast $^{\mathbf{z}}$ & $\mathbf{4}$ h before & Immed. before & Immed. after & 4 h after $^{\text {Immy }}$ \\
\hline AS 43.3 (10\%) vs. (50\%) & 0.100 & 0.001 & 0.001 & 0.138 \\
AS 43.4 (10\%) vs. (50\%) & 0.001 & 0.001 & 0.786 & 0.001 \\
OH 71.4 (10\%) vs. (50\%) & 0.001 & 0.001 & 0.001 & 0.001 \\
OH 182.9 (10\%) vs. (50\%) & 0.144 & 0.031 & 0.997 & 0.001 \\
\hline
\end{tabular}

y Time before and after antagonist; Immed. = immediately.

${ }^{\mathrm{z}}$ Antagonists were applied at concentrations of 10 or $50 \%$ of a 48-h antagonist-colonized, semidefined complete liquid medium.
G. zeae that were collected from three widely separated locations, it has yet to be seen how they will perform in field trials at different locations. Work will also be needed to enhance formulation technologies, including identifying additional compounds that could be used to preferentially enhance the activity of the biocontrol agents. In the absence of highly resistant cultivars or highly effective registered fungicides, this study confirms the potential of biological control as a viable option in an integrated pest management program for reducing scab of wheat.

\section{ACKNOWLEDGMENTS}

We thank C. P. Kurtzman and his collaborators C. J. Robnett, L. Tjarks, J. W. Fell, and T Boekhout for their expertise in identifying the yeast isolates; J. Ierulli for excellent technical assistance; and R. Dill-Macky for supplying wheat seed.

\section{LITERATURE CITED}

1. Andrés, L. J., Riera, F. A., and Alvarez, R. 1997. Recovery and concentration by electrodialysis of tartaric acid from fruit juice industries waste waters. J. Chem. Technol. Biotechnol. 70:247-252.

2. Bai, G., and Shaner, G. 1994. Scab of wheat: Prospects for control. Plant Dis. 78:760-766.

3. Bechtel, D. B., Kaleiku, L. A., Graines, R. L. and Seitz, L. M. 1985. The effects of Fusarium graminearum infection on wheat kernels. Cereal Chem. 62:191-197.

4. Casale, W. L., and Hart, L. P. 1988. Inhibition of ${ }^{3} \mathrm{H}$-leucine incorporation by trichothecene mycotoxins in maize and wheat tissue. Phytopathology 78:1673-1677.

5. Clear, R. M., and Patrick, S. K. 1990. Fusarium species isolated from wheat samples containing tombstone (scab) kernels from Ontario, Manitoba, and Saskatchewan. Can. J. Plant Sci. 70:1057-1069.

6. Dill-Macky, R., and Jones, R. K. 2000. The effect of previous crop residues and tillage on Fusarium head blight of wheat. Plant Dis. 84:71-76.

7. Gilbert, R. G., and Linderman, R. G. 1971. Increased activity of soil microorganisms near sclerotia of Sclerotium rolfsii in soil. Can. J. Microbiol. 17:557-562.

8. Hesseltine, C. W., Rogers, R. F., and Shotwell, O. 1978. Fungi, especially Gibberella zeae, and zearalenone occurrence in wheat. Mycologia 70:14-18.

9. Khan, N. I., Schisler, D. A., Boehm, M. J., Lipps, P. E., and Slininger, P. J. 1998. Developing strategies and organisms for biocontro of head scab of wheat. (Abstr.) Phytopathology 88:S47.

10. Lindow, S. E. 1988. Lack of correlation of in vitro antibiosis with antagonism of ice nucleation active bacteria on leaf surfaces by nonice nucleation active bacteria. Phytopathology 78:444-450.

11. McMullen, M., and Bergstrom, G. 1999. Chemical and biological control of Fusarium head blight: 1999 projects and progress. Pages 61-63 in: Proc. 1999 Nat. Fusarium Head Blight Forum. J. A. Wagester, R. Ward, L. P. Hart, S. P. Hazen, J. Lewis, and H. Border, eds. Michigan State University, East Lansing.

12. McMullen, M., Jones, R., and Gallenberg, D. 1997. Scab of wheat and barley: A reemerging disease of devastating impact. Plant Dis. 81:1340-1348.

13. Perondi, N. L., da Luz, W. C., and Thomas, R. 1996. Controle microbiológico da giberela do trigo, Fitopatol. Bras. 21:243-249. 
14. Proctor, R. H., Hohn, T. M., and McCormick, S. P. 1995. Reduced virulence of Gibberella zeae caused by disruption of trichothecene toxin biosynthesis gene. Mol. Plant-Microbe Interact. 8:593-601.

15. Reddy, M. S., Hynes, R. K., and Lazarovits, G. 1993. Relationship between in vitro growth inhibition of pathogens and suppression of pre-emergence damping-off and post-emergence root rot of white bean seedlings in the greenhouse by the bacteria. Can. J. Microbiol. 40:113-119.

16. Sato, I., Kobayasi, H., Hanya, Y., Abe, K., Murakami, S., Scorzetti, G., and Fell, J. W. 1999. Cryptococcus nodaensis sp. nov., a yeast isolated from soil in Japan that produces salt-tolerant and thermostable glutaminase. J. Ind. Microbiol. Biotechnol. 22:127-132.

17. Schisler, D. A., and Slininger, P. J. 1994. Selection and performance of bacterial strains for biologically controlling Fusarium dry rot of potatoes incited by Gibberella pulicaris. Plant Dis. 78:251-255.

18. Schisler, D. A., and Slininger, P. J. 1997. Mi- crobial selection strategies that enhance the likelihood of developing commercial biological control products. J. Ind. Microbiol. Biotechnol. 19:172-179.

19. Schisler, D. A., Slininger, P. J., Hanson, L. E., and Loria, R. 2000. Potato cultivar, pathogen isolate, and antagonist cultivation medium influence the efficacy and ranking of bacterial antagonists of Fusarium dry rot. Biocontrol Sci. Technol. 10:267-279.

20. Slininger, P. J., Schisler, D. A., and Bothast, R. J. 1994. Two-dimensional liquid culture focusing: A method of selecting commercially promising microbial isolates with demonstrated biological control capability. Pages 29-32 in: Improving Plant Productivity with Rhizosphere Bacteria. M. H. Ryder, P. M. Stephens, and G. D. Bowen, eds. 3rd Int. Workshop Plant Growth-Promoting Rhizobacteria. Graphic Services, CSIRO Division of Soils, Glen Osmond, Adelaide, Australia.

21. Snedecor, G. W., and Cochran, W. G. 1980. Statistical Methods. 7th ed. The Iowa State University Press, Ames.
22. Snijders, C. H. A. 1990. Fusarium head blight and mycotoxin contamination of wheat, a review. Neth. J. Plant Pathol. 96:187-198.

23. Stack, R. W., and McMullen, M. P. 1995. A visual scale to estimate severity of Fusarium head blight in wheat. N. D. State Univ. Ext. Serv. Bull. PP-1095.

24. Stockwell, C. A., da Luz, W. C., and Bergstrom, G. C. 1997. Biocontrol of wheat scab with microbial antagonists. (Abstr.) Phytopathology 87:S94.

25. Strange, R. N., and Smith, H. 1971. A fungal growth stimulant in anthers which predisposes wheat to attack by Fusarium graminearum. Physiol. Plant Pathol. 1:141150.

26. Strange, R. N., and Smith, H. 1978. Specificity of choline and betaine as stimulants of Fusarium graminearum. Trans. Br. Mycol. Soc. 70:187-192.

27. Vesonder, R. F., and Hesseltine, C. W. 1980. Vomitoxin: Natural occurrence on cerea grains and significance as a refusal and emetic factor to swine. Process Biochem. 16:12-15. 